

\title{
Flexural Behavior of Beams Fabricated Using Light Gauge Steel with Rectangular or Triangular Hollow Flanges
}

\author{
Tarek Sharaf ${ }^{1}$, Ashraf Elsabbagh ${ }^{2}$, Mohamed Abdellatif $^{3}$, and Mohamed Elghandour ${ }^{4}$
}

\begin{abstract}
Although the hot-rolled steel members have been considered as the most common and widely used steel profiles, but light gauge steel (LGS) use in structures is widely increasing recently. The structural attitude of this light gauge is characterized by different buckling modes as local, distortional, and torsional buckling. Light gauge steel sections are being produced in many forms. One of these forms is the hollow flanged beam sections which proved its effectiveness but their behavior still not fully understood. In this paper, the moment behavior of LGS beams is verified using the finite element analysis. A numerical study was applied to figure out the parameters affecting the behavior of the LGS beams in case of using hollow flanges, either rectangular or triangular, with and without vertical stiffening under flexural loading. All beams were simply supported and subjected to two-point loadings configuration. The ultimate load capacity and failure mode of all beams were determined. Three different design codes were utilized to validate the results.
\end{abstract}

KEYWORDS: Rectangular hollow flange steel beams, Triangular hollow flange steel beams, Finite element analysis, Light gauge steel, Design standards, Local buckling failure.

\section{INTRODUCTION}

There are two main types of structural steel members which are being used in steel structures, hot-rolled steel members and light gauge steel which are known as coldformed steel members. Light gauge steel members markets contain purlin applications, beams, and columns of industrial, commercial, and frameworks. Light gauge steel sections usage in the construction industries is extensively expanded due to their simplicity shaping at room temperatures, high strength to weight ratio, simplicity of erection and fabrication, and economy of transportation and handling. These advantages can affect in more costeffective designs, particularly in short span applications. Light gauge steel sections are ordinarily manufactured into $\mathrm{C}, \mathrm{Z}$, hat, and rack sections. These sections are common because of their simple forming procedures and easy connections, but they face some problems due to buckling modes as a result of their high plate slenderness, eccentricity of shear center to centroid, and low torsional rigidity.

Recently, many attempts have been taken to dispose of the occurrence of such buckling modes and enhance the load carrying capacities of cold-formed steel members. One of these attempts is the hollow flange section (HFS). These sections are shaped by creating two torsionally rigid closed flanges and a slender web. HFS are lighter in weight than hot-rolled steel sections, also are more effective than hotrolled steel members. Recently, different types have been developed in the building and construction industries. These types are Hollow Flanged Beams (HFB), Lite Steel Beams (LSB), Figure 1 (a and b), respectively. The HFBs are special cold-formed steel sections made for use as flexural members.
RHFB are fabricated from a single strip of high strength steel sheet using electric resistance welding. These sections were developed to be the new rectangular hollow flange sections which consist of two separated rectangular flanges connected to a slender web plate using screws, rivets or weld, as shown in Figure 1 (c).

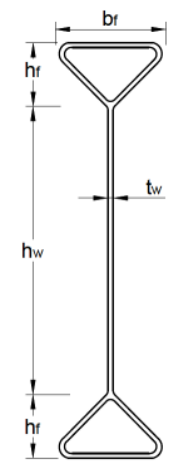

(a) HFB



(b) LSB

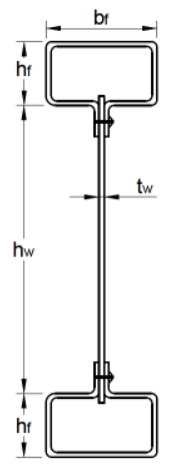

(c) RHFB
Figure 1: Types of hollow flanged beam sections.

These symmetrical members have been used as flexural and axially loaded members. Avery and Mahendran [1] presented finite element models, analytical results, and large scale experiments for the HFBs with web stiffeners to evolve the lateral torsional buckling capacity for such beams. Trahair [2] at first found a solution for the influence of elastic lateral distortion buckling on HFBs under flexural moment, then predicted the effects of the imperfections in section geometry, residual stresses, and stress-strain curve on the strength of beams which have failed due to lateral-distortional buckling.

\footnotetext{
${ }^{1}$ Assistant Professor, Faculty of Engineering, Civil Engineering Department, Port Said University, Email: ttsharaf@hotmail.com

${ }^{2}$ Assistant Professor, Faculty of Engineering, Civil Engineering Department, Port Said University, Email: ashraf_ims@yahoo.com

${ }^{3}$ Master Student, Faculty of Engineering, Civil Engineering Department, Port Said University, Email: engmsol80@gmail.com

${ }^{4}$ Professor, Faculty of Engineering, Civil Engineering Department, Port Said University, E-mail: dr.elghandor@gmail.com
} 
These symmetrical members have been used as flexural and axially loaded members. Avery and Mahendran [1] presented finite element models, analytical results, and large scale experiments for the HFBs with web stiffeners to evolve the lateral torsional buckling capacity for such beams. Trahair [2] at first found a solution for the influence of elastic lateral distortion buckling on HFBs under flexural moment, then predicted the effects of the imperfections in section geometry, residual stresses, and stress-strain curve on the strength of beams which have failed due to lateral-distortional buckling. Zhao [3] investigated the structural attitude and design of HFB sections as compression elements. Riveting and screw fastening were used to form (RHFB) sections, so the structural attitude and design of RHFB as flexural members will be different because of that. Somadasa [4] provided large scale study about the attitude and design of (RHFB) made of separated flanges connected to the web using screw fastening under flexural loading. The Lite Steel Beams (LSBs) have an individual shape and industrialization process which gives more effective strength to weight ratio. It has probably vast range of applications between residential, industrial, and manufacturing construction.

Many researches have been performed within the structural behavior and the design of LSBs. Both experimental testing and FEA have been achieved to improve the behavior and design of LSBs, under flexure [5-8] and under shear [9-12]. Mahendran and Mahaarachchi [13] presented an experimental examination of section moment capacity of cold formed C-section beams with hollow flanges. The results were validated with predicted moment capacities from the current design standards. Wilkinson et al. [14] investigated the behavior of $\mathrm{C}$-section beams with rectangular hollow flange using interior one flange loading condition to increase the strength to web crippling. Jeyaragan and Mahendran [15] experimentally and numerically investigated the LSBs to understand their behavior with different connection spacing under flexure.

Kurniawan and Mahendran [16] presented a study about the lateral buckling strength of LSBs in simply support condition using finite element analysis under gradient moment effects. Then presented lateral buckling experiments to validate the results of the finite element analysis and provided design recommendations for such beams. Kurniawan and Mahendran [17] presented a numerical study on LSBs based on lateral buckling strength under transverse loading using design modification factor from various steel design codes. Raghul and Maheswari [18] presented an analytical investigation to study the lateral torsional and distortional buckling using numerical non-linear simulation on $\mathrm{C}$ shaped and R-shaped beams under flexure using twopoint load conditions. The study also investigated the influence of the width and depth of the beam on its structural behavior. Mahendran [19] presented some applications on cold formed steel sections in structural engineering using finite element analysis.

It was found that few researches studied the effect of using stiffeners to improve the section behavior. Also, the new rectangular hollow flange section has been chosen for this study because its behavior was different from HFB and LSB due to the semi discontinuity along the web to flange connections. The separation between flanges and web in these sections allows the use of different flanges and web thicknesses, which makes structural optimization goes well with the different applications of such beams. Depending on these features it is possible to study the behavior of Triangular Hollow Flanged beams (THFBs) as well and compare results to find out which section is more effective. This study considers the flexural behavior of hollow flange beams with and without stiffeners using FEA. The use of vertical stiffeners could enhance the lateral distortional buckling moment capacities as there are no predicting design guides for the expected failure modes. So, the changing in section parameters, steel grade, stiffening condition, and span could be useful to improve the results.

\section{FINITE ELEMENT MODELLING}

\subsection{General}

The finite element analysis was implemented to simulate the behavior of the RHFBs under flexure using ANSYS®. The appropriate geometric parameters, mechanical properties, initial geometric imperfections, supporting conditions, and loading conditions were taken into consideration. The ultimate strengths, failure modes, moment-displacement curves of these sections were observed and monitored. All results were verified against the experimental results obtained by Somadasa [4] to verify the finite element models.

\subsection{Finite Element Meshing}

In the simulation process, the shell element was used to simulate the behavior of the RHFBs, SHELL181 element [20] was used for all section parts. It is an element with four-nodes and each node has six degrees of freedom, as shown in Figure 2.



Figure 2: Shell 181 with four nodes and six degree of freedom for each node.

SHELL181 is appropriate for linear and large rotation applications as well as for large strain nonlinear 
applications. In the FEA, accurate results depend on the density of the mesh used to simulate the model. It is suitable to increase the number of elements in the generated mesh to enhance accuracy. Mesh sensitivity analysis has been done to estimate the most appropriate mesh size which produces the most accurate results. Figure 3 shows three mesh sizes for RHFB-150hw-1.2tf1.2tw-G300; fine mesh $5 \times 5 \mathrm{~mm}^{2}$, medium mesh $10 \times 10$ $\mathrm{mm}^{2}$ and coarse mesh $15 \times 15 \mathrm{~mm}^{2}$. The relationship between moment and deflection for different mesh sizes are shown in Figure 4. The results for the three types were too close, for that the medium mesh with size $10 \times 10 \mathrm{~mm}^{2}$ has been chosen to save analysis run time and to get the required accuracy for analysis as well as a uniform deformed shape.

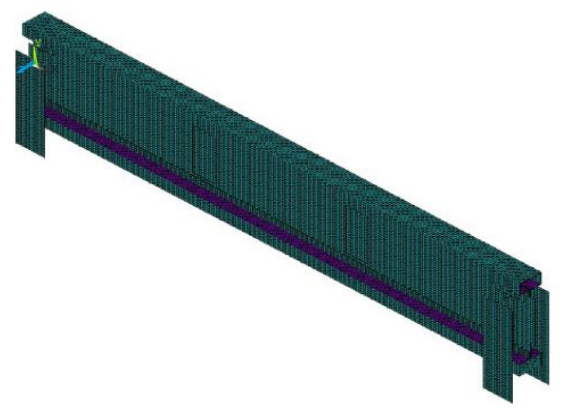

(a) Fine $\left(5 \times 5 \mathrm{~mm}^{2}\right)$

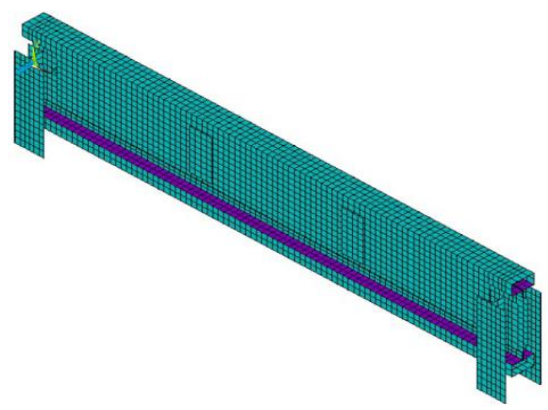

(b) Medium $\left(10 \times 10 \mathrm{~mm}^{2}\right)$

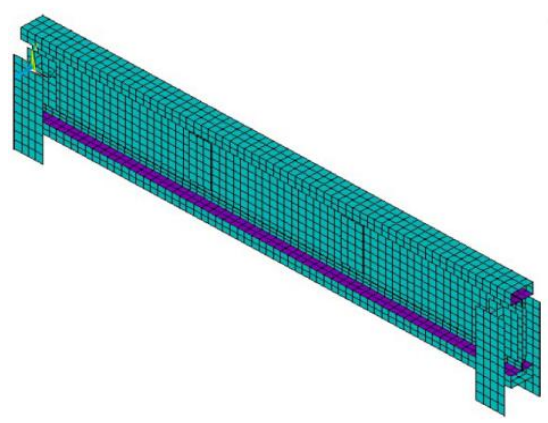

(C) Coarse $\left(15 \times 15 \mathrm{~mm}^{2}\right)$

Figure 3: Three different finite element meshes: fine,

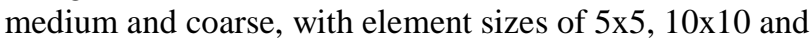
$15 \times 15 \mathrm{~mm}^{2}$.

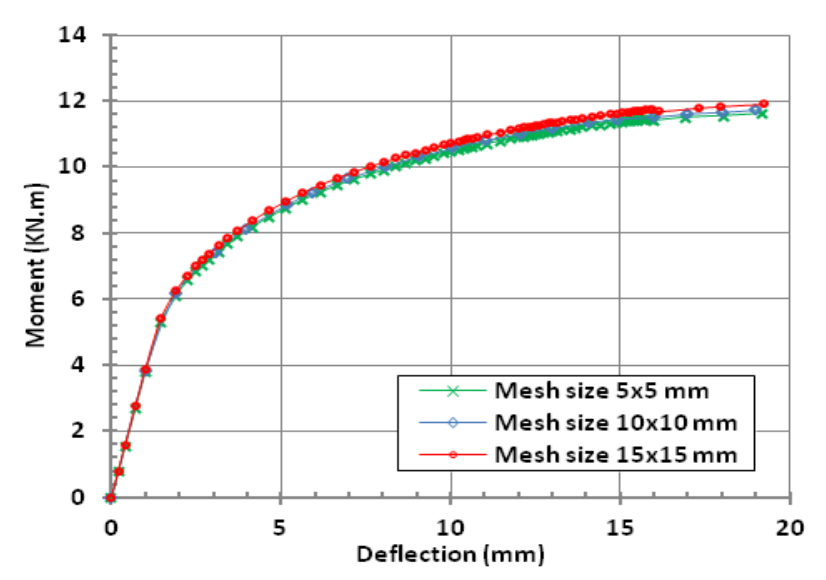

Figure 4: Mesh sensitivity analysis results for RHFB150hw-1.2tf-1.2tw-G300.

\subsection{Material Model}

The FEA considers the von Mises general multi linear plasticity to characterize kinematic hardening plasticity. Poisson's ratio was taken 0.3 and modulus of elasticity was taken $200 \mathrm{GPa}$. Somadasa [4] presented the stressstrain curves which characterize the results of the tensile test specimens for the steel grades G300 and G500. Figure 5 shows the values of the yield stress $\left(F_{y}\right)$, ultimate tensile stress $\left(F_{u}\right)$, and modulus of elasticity $(E)$. For G500, the yield stress was calculated by using the $0.2 \%$ proof stress method, and for G300 the yield stress was calculated from the graph at the sharp yield points. The yield stress for the G300 steel was $334.25 \mathrm{MPa}$ while it was $580 \mathrm{MPa}$ for the G500 steel.
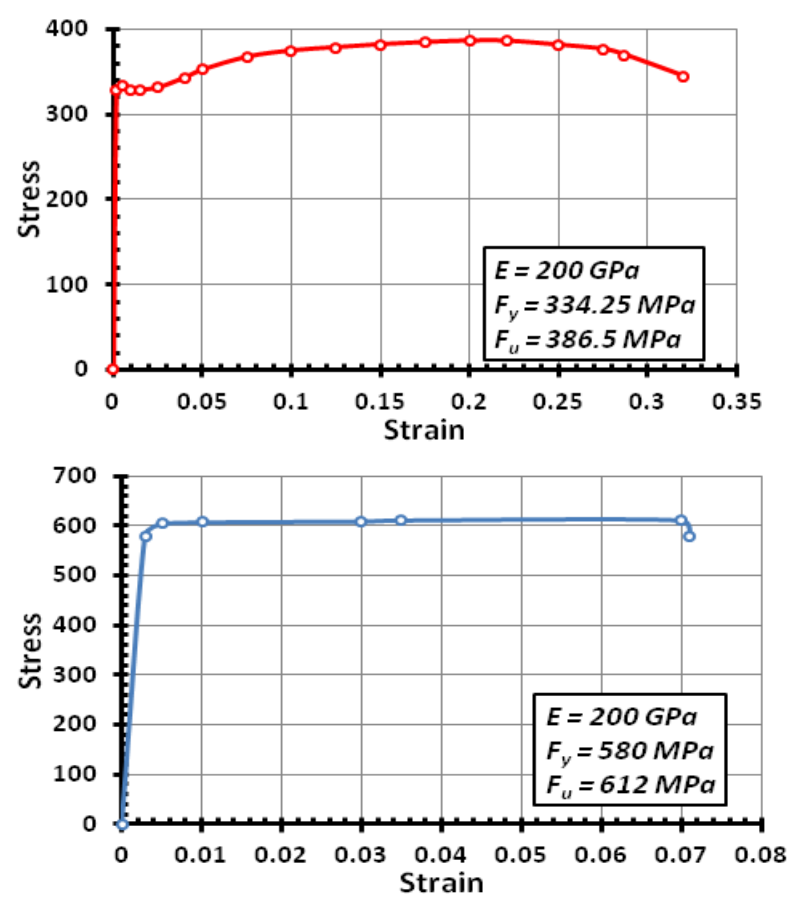

Figure 5: Tensile stress versus strain curves for different steel grades [4]. (a) for steel grade G300 and (b) for steel grade G500. 


\subsection{Loads and Boundary Conditions}

All experimental models were tested under two-point loading with simple support conditions, Somadasa [4], as shown in Figure 6. This loading condition insures a uniform bending moment at the middle region of the tested beams. All models were supported on half rounds placed on a ball bearing, which achieve the requirements of simply supported conditions. The FE models were simulated to present the same loading and boundary conditions in the test procedures as shown in Figure 7.

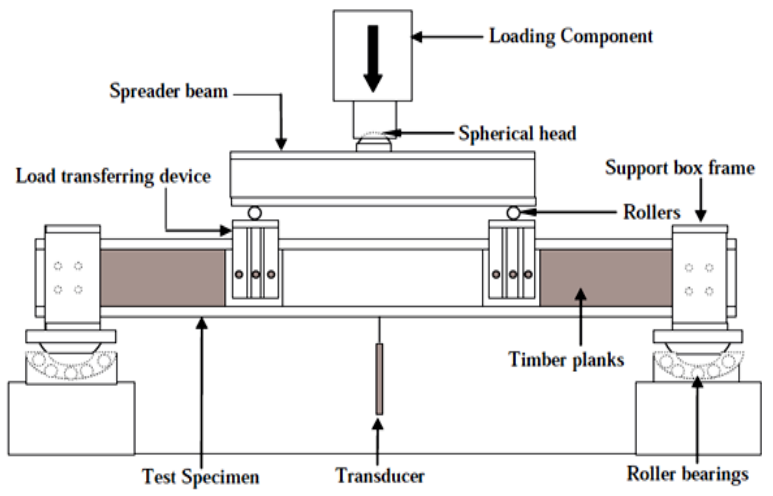

Figure 6: Test set up for section moment capacity tests used in Somadasa [4].

As a result, the right and left supports have been prevented from displacements ( $\mathrm{Uy}$ and $\mathrm{Uz}$ ) in the $\mathrm{y}$ and $\mathrm{z}$ directions also, the rotations $(\theta \mathrm{x}$ and $\theta \mathrm{y})$ about $\mathrm{x}-$ and $\mathrm{y}$ axes was prevented, which makes the support able to rotate about the z-axis only. The points at mid span were prevented from displacement in the $\mathrm{x}$-direction to maintain the model stability. The points of loading were permitted to displace in the vertical direction (as a displacement loading) and the beam loading capacity were calculated from the reactions at supports. Screws are simulated by coupling nodes at the location of the screw. At which, points on the web plates were master points and flange points are slave points, this procedure assures that points in this location are similar to the experimental boundary conditions, as shown in Figure 8.

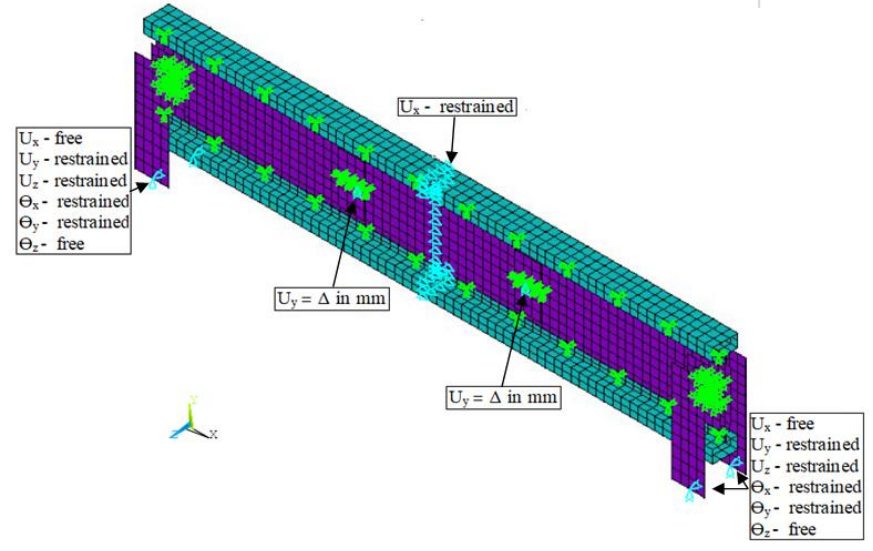

Figure 7: A finite element meshing, loading and boundary conditions for section moment capacity tests.

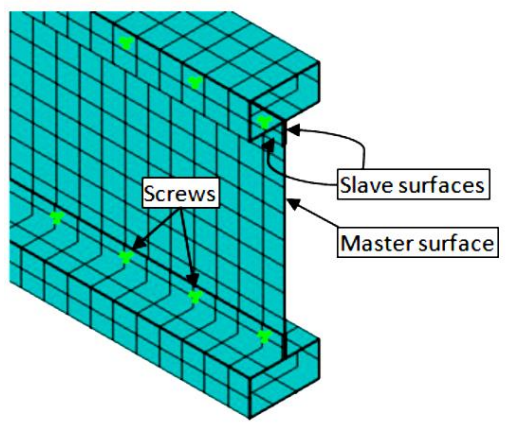

Figure 8: Coupling and surfaces definitions.

\subsection{Initial Geometric Imperfections}

The initial geometric imperfections effect was considered in the FEA of the HFB. there is no specific characterization provided to the existing imperfection data but only a limited characterization. The maximum imperfection data were not taken as a value which the imperfection values is usually simulated of the real beam imperfection. True imperfection magnitude and distributions are obscure. The value of initial imperfection was taken as $d 1 \approx 6 t^{-2}$ as the overall geometric imperfection in the FEM based on Schafer and Pekoz [21]. To account for the initial geometric imperfection in the nonlinear analysis, elastic buckling analysis was carried out. The resulted first and worst buckling mode was used to represent the initial geometric imperfection. Hence, in this analysis, the worst possible deformation mode was considered as a one of twenty eigenbuckling modes and was used in the nonlinear FE model. In this study, the worst buckling mode was considered as the last buckling mode. The geometric update ratio could be taken from Equation (1). Figure 9 illustrates an example for the buckling mode which considered the worst mode of buckling for RHFB-150hw-0.95tf-0.55tw-G550 beam.

geometric updating ratio $=\left(\frac{\text { initial imperfection value }}{\text { max.deformation value }}\right)$

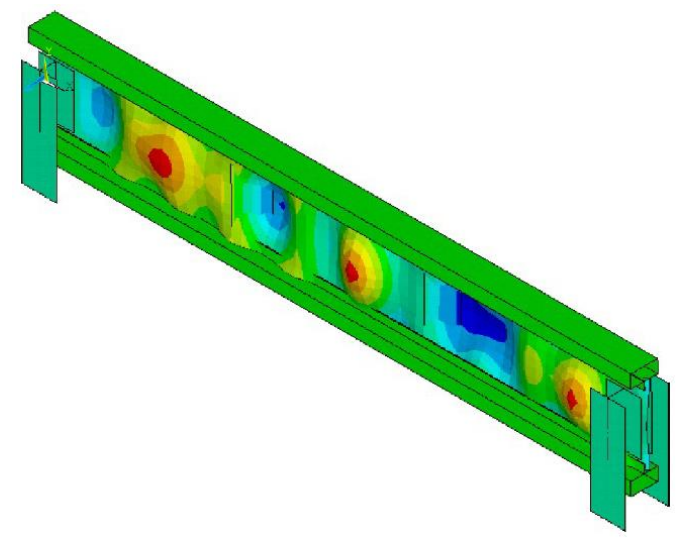

Figure 9: local buckling model for RHFB-150hw-0.95tf$0.55 \mathrm{tw}-\mathrm{G} 550$ (mode 20$)$. 


\subsection{Residual Stresses}

During the structure procedure concerning cold-formed steel sections, residual stresses are induced inside the cross-section. While the net effect on residual stresses need to be naught for equilibrium, the existence of residual stresses performs result within precocious yielding of plate elements. Two types of residual stresses are existed between the cold-formed steel structural members and they are:

1) Membrane residual stresses.

2) Bending residual stresses.

Wan and Mahendran [22] studied the effect of residual stresses on LSBs and found that their effect on the ultimate loads was small, depending on that, the effect of residual stresses has been neglected in this research.

\section{VERIFICATION OF THE FINITE ELEMENT MODEL}

There was a total of twenty-two section moment capacity tests that have been presented in Somadasa [4], all test specimens had a $1130 \mathrm{~mm}$ span. The cross-section dimensions are listed in Table 1 for five section moment capacity tests. Typical moment-vertical deflection curves as well as moments-strain for the chosen beams were verified for the following beam cases:

1) Equal flange and web thicknesses $\left(t_{f}=t_{w}\right)$,

2) Flange thickness is larger than web thickness $\left(t_{f}>t_{w}\right)$,

3) Flange thickness is less than web thickness $\left(t_{f}<t_{w}\right)$.

The vertical deflection curves illustrate the deflection at the bottom flange of beam mid-span. A typical moment against deflection curves for RHFBs are shown in Figure 10 while the moment against strains is shown in Figure11.
Table 1: Nominal dimensions of verified section moment capacity beams taken from Somadasa[4].

\begin{tabular}{cccccc}
\hline Model & $\begin{array}{c}\mathrm{h}_{\mathrm{w}} \\
(\mathrm{mm})\end{array}$ & $\begin{array}{c}\mathrm{t}_{\mathrm{f}} \\
(\mathrm{mm})\end{array}$ & $\begin{array}{c}\mathrm{t}_{\mathrm{w}} \\
(\mathrm{mm})\end{array}$ & $\begin{array}{c}\text { Steel } \\
\text { Grade }\end{array}$ & $\begin{array}{c}\text { Screw } \\
\text { Spacing } \\
(\mathrm{S})\end{array}$ \\
\hline 1 & 100 & 1.2 & 0.55 & $\mathrm{G} 300$ & 50 \\
\hline 2 & 100 & 1.2 & 0.55 & $\mathrm{G} 300$ & 100 \\
\hline 3 & 150 & 1.2 & 1.2 & $\mathrm{G} 300$ & 50 \\
\hline 5 & 150 & 1.2 & 0.55 & $\mathrm{G} 300$ & 50 \\
\hline 5 & 150 & 0.95 & 0.55 & $\mathrm{G} 550$ & 100 \\
\hline
\end{tabular}

Refer to Figure 1c.

where $h_{f}=25 \mathrm{~mm}, b_{f}=50 \mathrm{~mm}$ and $h_{L}=15 \mathrm{~mm}$

Figures 10-11 show a good agreement between the FEA results compared to the experimental investigation. The deviations among FEA and experimental outcomes have been regarded to be due to feasible variations and errors in the deflection measurements [4], also it could have been due to the friction at the support bearings. This was not measured, and no try was made to contain the friction effects [4]. However, the effect of the friction in the bearings on buckling moment was considered to be small [4]. 

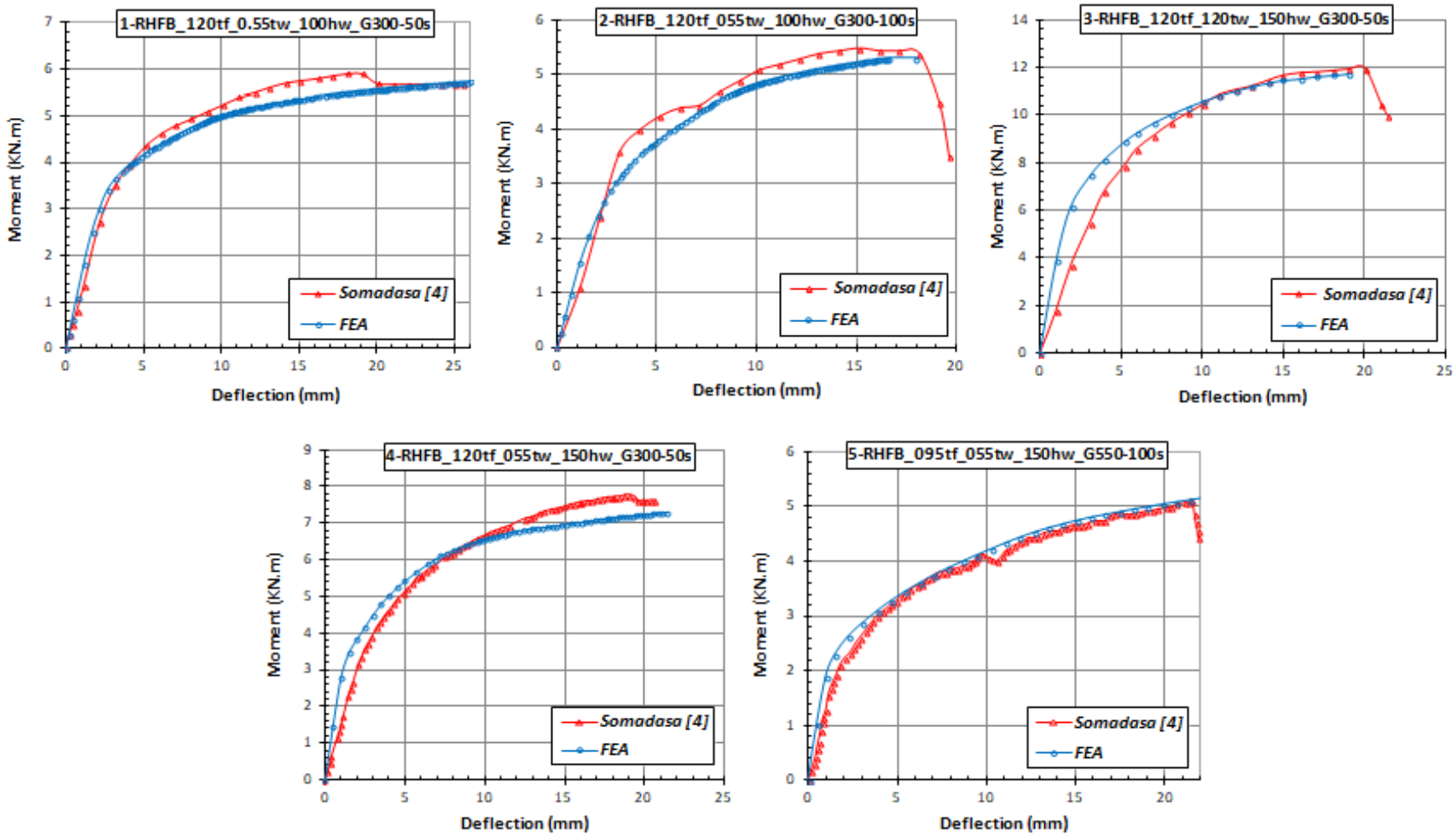

Figure 10: Moment versus deflection curves for RHFBs.

In Figure 11, the strains were measured at the bottom and top surfaces of the flanges at the mid-span of the modeled beams. Tension strain was regarded as positive while compression strain was regarded as negative. Consequently, the negative side represents both the experimental and FEA curves for the compression flange and positive side represents those curves for the tension flange. These curves show that the FEA and experimental results are in good agreement.

Figure 12 compares the deformed shape obtained from FEA with the deformed shape obtained from the experimental test. The local buckling of top flange plate or web are the most common failure modes of RHFBs at shorter spans, these modes depend on the flange and web slenderness. As shown in Figure 12, local buckling appeared on the top flange plate. Based on the overall comparison of FEA and the experimental test through the failure modes, moment-strain curves, and momentdeflection curves, the FEA can be effectively used to investigate, parametrically, the behavior of the RHFBs with different cross sections dimensions, different spans, and with or without stiffeners. 

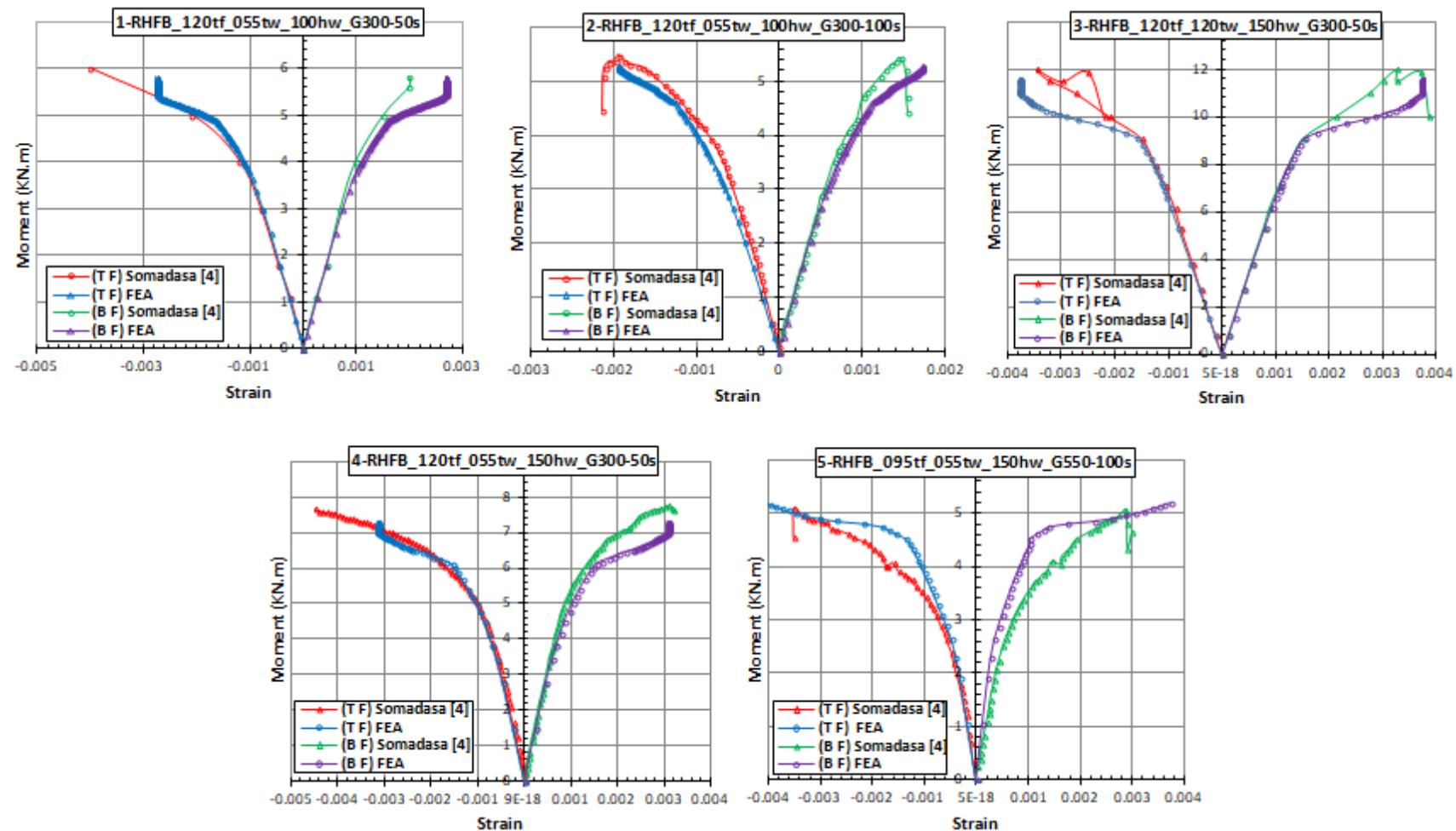

Figure 11: Moment versus strain curves for RHFBs.

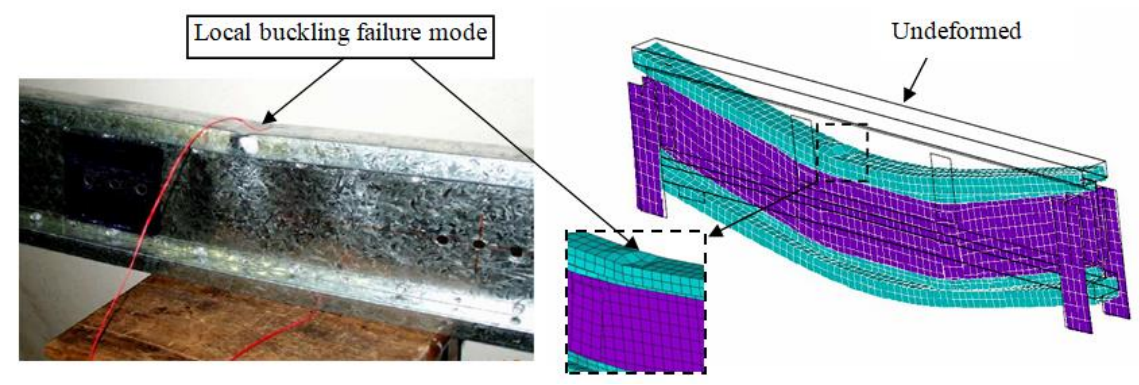

Figure 12: Comparison of experimental and numerical failure mode of beam specimens at ultimate load.

\section{PARAMETRIC STUDY OF BEAMS WITH HOLLOW FLANGES}

As a result of the verification using the finite element analysis, the parametric study was carried out based on the verified models to develop a comprehensive database about the behavior of hollow flange beams under flexure. In this investigation, a total of 96 hollow flange models, grouped as 48 models for the beams with rectangular hollow flange beams (RHFBs), Figure 13a, and the other 48 models were for triangular hollow flange beams
(THFBs), Figure 13b. Every group contained three different spans $(2000 \mathrm{~mm}, 3000 \mathrm{~mm}$ and $4000 \mathrm{~mm})$ and two different steel grades (G300 and G500). Every steel grade has 8 models with four stiffening conditions; no stiffeners (control), every $0.05 \mathrm{~L}, 0.1 \mathrm{~L}$, and $0.2 \mathrm{~L}$. The stiffeners were located at the first and last quarters of the whole span. Table 2 summarizes the FEA model dimensions while Figure 14 shows the HFB dimensions and stiffeners locations for the whole beam span. 


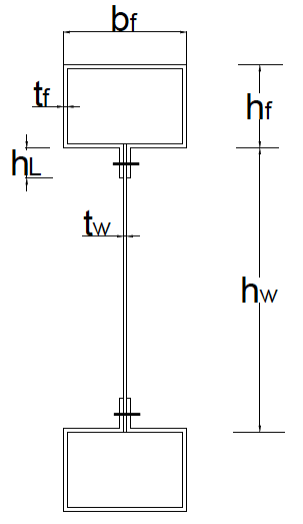

(a)

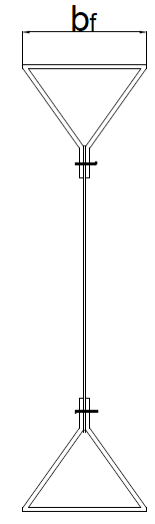

(b)
Figure 13: Cross sections of hollow flanged beams (a) RHFB and (b) THFB.

\section{ANALYTICAL INVESTIGATION}

This part investigates the effective width method. The effective cross section gives a reasonably accurate explanation of the locations of which part of the section is ineffective in carrying loads and explains the neutral axis shifts within the section due to the local-buckling. The effective width theory has been extensively used for the computation of ultimate strength of Light gauge steel members. Many design codes use effective width theory in order to recompense for the stiffness decrease in the post-buckling stage. North American and European design codes give only expressions for the calculation of the elastic buckling loads for plates under this load set. The distribution of stresses on a plate after buckling is clearly non-linear, with lower stresses values on the central part and maximum stresses at the edges of the plate equal to the yield stress $\mathrm{F}_{\mathrm{y}}$.

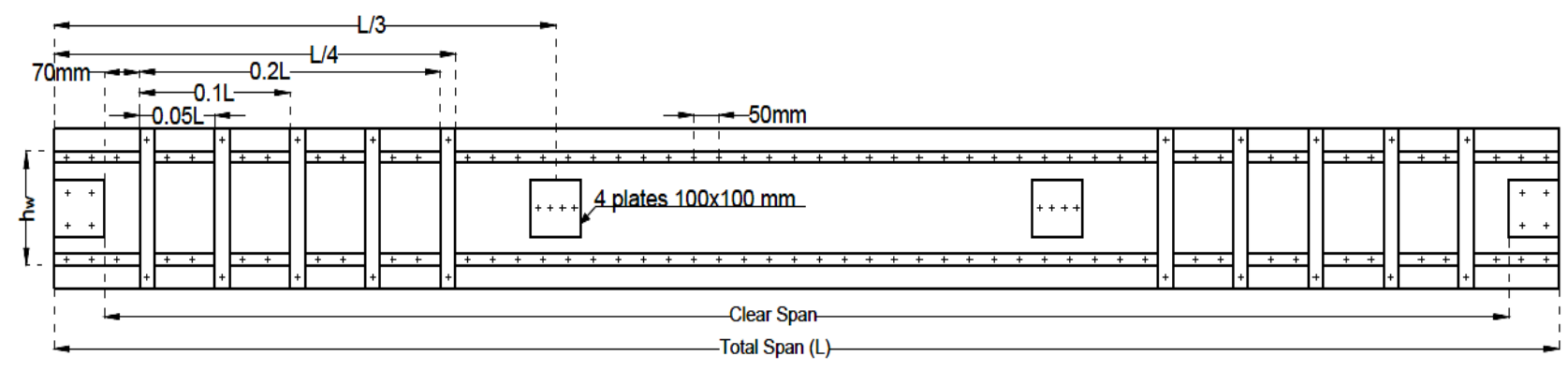

Figure 14: Definition of location of stiffeners for the whole span

Table 2: Dimensions and stiffening conditions for (RHFBs and THFBs) for different spans and steel grades

\begin{tabular}{|c|c|c|c|c|c|c|c|c|c|c|c|}
\hline \multirow[b]{2}{*}{ Beam } & \multicolumn{2}{|c|}{ Web } & \multicolumn{4}{|c|}{ Flange } & \multirow[b]{2}{*}{ Screw Spacing } & \multicolumn{4}{|c|}{ Stiffeners along L/4 from Support } \\
\hline & $\begin{array}{c}\mathrm{h}_{\mathrm{w}} \\
(\mathrm{mm})\end{array}$ & $\begin{array}{c}\mathrm{t}_{\mathrm{w}} \\
(\mathrm{mm})\end{array}$ & $\begin{array}{c}\mathrm{h}_{\mathrm{f}} \\
(\mathrm{mm})\end{array}$ & $\begin{array}{c}\mathrm{b}_{\mathrm{f}} \\
(\mathrm{mm})\end{array}$ & $\begin{array}{c}\mathrm{t}_{\mathrm{f}} \\
(\mathrm{mm})\end{array}$ & $\begin{array}{c}\mathrm{h}_{\mathrm{L}} \\
(\mathrm{mm})\end{array}$ & & $\begin{array}{c}\mathrm{h}_{\mathrm{s}} \\
(\mathrm{mm}) \\
\end{array}$ & $\begin{array}{c}\mathrm{t}_{\mathrm{s}} \\
(\mathrm{mm})\end{array}$ & $\begin{array}{l}\text { width } \\
(\mathrm{mm})\end{array}$ & Spacing \\
\hline $\begin{array}{l}\text { HFB1 } \\
\text { HFB2 }\end{array}$ & 200 & $\begin{array}{c}0.55 \\
1.2 \\
\end{array}$ & 40 & 50 & $\begin{array}{c}1.2 \\
0.55 \\
\end{array}$ & 20 & 50 & \multicolumn{4}{|c|}{ No Stiffeners (Control) } \\
\hline $\begin{array}{l}\text { HFB1 } \\
\text { HFB2 }\end{array}$ & 200 & $\begin{array}{c}0.55 \\
1.2 \\
\end{array}$ & 40 & 50 & $\begin{array}{c}1.2 \\
0.55 \\
\end{array}$ & 20 & 50 & 280 & 1.2 & 30 & $0.05 \mathrm{~L}$ \\
\hline $\begin{array}{l}\text { HFB1 } \\
\text { HFB2 }\end{array}$ & 200 & $\begin{array}{c}0.55 \\
1.2\end{array}$ & 40 & 50 & $\begin{array}{c}1.2 \\
0.55\end{array}$ & 20 & 50 & 280 & 1.2 & 30 & $0.1 \mathrm{~L}$ \\
\hline $\begin{array}{l}\text { HFB1 } \\
\text { HFB2 }\end{array}$ & 200 & $\begin{array}{c}0.55 \\
1.2 \\
\end{array}$ & 40 & 50 & $\begin{array}{c}1.2 \\
0.55\end{array}$ & 20 & 50 & 280 & 1.2 & 30 & $0.2 \mathrm{~L}$ \\
\hline
\end{tabular}

The effective width method with the effect of the geometrical imperfections and the residual stresses converts the plate width, $b$, into an imaginary plate with an effective width of $b_{\text {eff }}$ and a uniform stress distribution equals to the yield stress $F_{y}$, as shown in Figure 15.

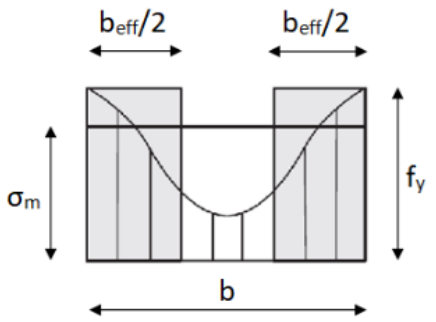

Figure 15: Effective width concept.

In this paper, there are three design codes that have been used to predict the section load carrying capacity for cold formed steel sections, namely:

1) Euro Code [23-24]. 
2) AISI Code [25].

3) ECP code [26].

\subsection{Euro code}

Effective width:

$$
b_{e}=\rho \times b
$$

For internal compression elements:

$$
\begin{array}{r}
\rho=1.0 \quad \text { for } \lambda p \leq 0.5+\sqrt{0.085-0.055 \Psi} \\
\rho=\frac{\lambda \mathrm{p}-0.055(3+\Psi)}{\lambda_{\mathrm{p}}^{2}}<1.0 \\
\text { for } \lambda p \leq 0.5+\sqrt{0.085-0.055 \Psi}
\end{array}
$$

For flange type:

$$
\begin{array}{ll}
\rho=1.0 & \text { for } \lambda p \leq 0.748 \\
\rho=\frac{\lambda \mathrm{p}-0.188}{\lambda_{\mathrm{p}}^{2}}<1.0 \quad \text { for } \lambda p>0.748 \\
\lambda \mathrm{p}=\sqrt{\frac{\mathrm{F}_{\mathrm{y}}}{\sigma_{\mathrm{cr}}}}=\frac{\frac{\mathrm{b}_{\mathrm{p}}}{\mathrm{t}}}{28.4 \times \sqrt{\frac{235}{\mathrm{f}_{\mathrm{y}}}} \times \sqrt{\mathrm{K}_{\sigma}}}
\end{array}
$$

where $F_{y}$ in $\mathrm{N} / \mathrm{mm}^{2}$ and $\mathrm{K}_{\sigma}$ is the relevant buckling factor

$\Psi=\frac{\mathrm{f}_{2}}{\mathrm{f}_{1}}$

where $f_{1}, f_{2}$ are the stress distribution on element edges

For

$$
\begin{array}{ll}
\Psi=1 & K \sigma=4.0 \\
1>\Psi>0 & \mathrm{K \sigma}=\frac{8.2}{1.05+\Psi} \\
\Psi=-1 & K \sigma=23.9
\end{array}
$$

\subsection{AISI Code:}

Effective width:

$$
\begin{aligned}
& b=w \\
& b=\rho w
\end{aligned}
$$$$
\text { when } \lambda \leq \mathbf{0 . 6 7 3}
$$$$
\text { when } \lambda>0.673
$$

$$
\begin{aligned}
& \rho=\frac{\left(1-\frac{0.22}{\lambda}\right)}{\lambda} \\
& \lambda=\sqrt{\frac{\mathrm{F}_{\mathrm{y}}}{\mathrm{F}_{\mathrm{cr}}}} \\
& \mathrm{F}_{\mathrm{cr}}=\mathrm{K} \frac{\pi^{2} \mathrm{E}}{12\left(1-\mu^{2}\right)}\left(\frac{\mathrm{t}}{\mathrm{w}}\right)
\end{aligned}
$$

Where:

$w=$ Plat width

$K=$ Plate buckling coefficient

$E=$ Modulus of elasticity of steel

$\mu=$ Poisson's ratio of steel

$$
\Psi=\frac{\sigma_{2}}{\sigma_{1}} \quad \begin{aligned}
& \text { where } \quad \sigma_{1}, \sigma_{2} \text { are the stress } \\
& \text { distribution on element edges }
\end{aligned}
$$

For

$$
\begin{array}{ll}
\Psi=1 & \mathrm{~K}=4.0 \\
1>\Psi & \mathrm{K}=4+2(1-\Psi) 3+2(1-\Psi) \\
>0 & \mathrm{~K}=23.9 \\
\Psi=-1 &
\end{array}
$$

\subsection{ECP Code:}

Effective width:

$b_{e}=\rho \times b$

$\rho=\frac{(\lambda p-0.15-0.05 \Psi)}{\lambda_{p}^{2}} \leq 1$

$\lambda \mathrm{p}=\frac{\mathrm{b} / \mathrm{t}}{44} \sqrt{\frac{\mathrm{Fy}}{\mathrm{K} \sigma}}$

Where:

$\mathrm{K} \sigma=$ plate buckling factor which depends on the stress ratio $\Psi$

$\mathrm{b}=$ appropriate width

$\Psi=\frac{f_{2}}{f_{1}} \quad$ where $\mathbf{f}_{1}, \mathbf{f}_{2}$ stress distribution on

If

$\Psi=1 \quad K \square=4.0$

$1>\Psi>0 \quad K \square=\frac{8.2}{1.05+\Psi}$

$\Psi=-1 \quad K \square=23.9$ 


\subsection{DETERMINATION OF CRITICAL LOAD (P)}

$M=\frac{P L}{3}$

\section{PARAMETRIC AND ANALYTICAL RESULTS}

\subsection{Analysis of Control Beams}

Tables 3 and 4 show a comparison between the loads obtained from the finite element analysis and the critical load calculated from the current design codes to calibrate the models. It was found that the results from the FEA showed a good agreement. Also, the critical load of each model at failure is presented and compared with those predicted based on the ECP, the AISI and the Euro codes. This comparison shows that both design methods are close in general. AISI code [25] estimates the critical loads for G300 with a mean $=15.47$ and a coefficient of variation (COV) of 0.504 for the RHFBs and with a mean $=13.49$ and COV of 0.497 for the THFBs. While for G500 steel beams, the AISI code estimates the critical loads with mean $=26.15$ and a COV of 0.509 for the RHFB and with mean $=22.85$ and a COV of 0.503 for the THFBs. On the other hand, the Euro code [23-24] estimates the critical loads for G300 with mean $=15.54$ and a $\mathrm{COV}$ of 0.504 for the RHFBs and with mean $=13.56$ and a COV of 0.496 for the THFBs. While for the G500 steel beams,
Where $P$ is the reaction at the support

$$
\begin{aligned}
& \mathrm{F}_{\mathrm{y}}=\frac{\mathrm{M} \mathrm{Y}}{\mathrm{I}_{\mathrm{x}}} \\
& \mathrm{P}_{\mathrm{cr}}=\frac{3 \mathrm{~F}_{\mathrm{y}} \mathrm{I}_{\mathrm{x}}}{\mathrm{Y} \mathrm{L}}
\end{aligned}
$$

the Euro code estimates the critical loads with mean = 26.31 and a COV of 0.509 for the RHFB and with mean = 22.96 and a COV of 0.503 for the THFBs. ECP code [26] estimates the critical loads for G300 with a mean $=15.56$ and a coefficient of variation (COV) of 0.502 for the RHFBs and with a mean $=13.573$ and COV of 0.495 for the THFBs. While for G500 steel beams, the ECP code estimates the critical loads with mean $=26.36$ and a COV of 0.508 for the RHFB and with mean $=22.997$ and a COV of 0.5013 for the THFBs. For the FEA models, the failure loads validated with estimated design capacities could be attributed to their initial geometric imperfection, which could have effect on the section critical load capacities of HFBs. The separation between the web and flange plates due to interrupted screw fastening could have also decrease the section load capacities of HFBs. It should also be noted that neither AISI nor Euro codes is taking into account the screws patterns into account during calculating the cross-section load capacity.

\begin{tabular}{|c|c|c|c|c|c|c|c|c|c|c|c|c|c|c|c|c|}
\hline \multirow{3}{*}{ Model } & \multirow{3}{*}{$\begin{array}{c}\text { Steel } \\
\text { Grade }\end{array}$} & \multirow{3}{*}{$\begin{array}{l}\text { Clear } \\
\text { Span }\end{array}$} & \multicolumn{7}{|c|}{ RHFB } & \multicolumn{7}{|c|}{ THFB } \\
\hline & & & \multicolumn{4}{|c|}{ Critical load } & \multirow{2}{*}{$\left(\frac{\mathrm{FEA}}{\mathrm{ECP}}\right)$} & \multirow{2}{*}{$\left(\frac{\mathrm{FEA}}{\mathrm{EURO}}\right)$} & \multirow{2}{*}{$\left(\frac{\mathrm{FEA}}{\mathrm{AISI}}\right)$} & \multicolumn{4}{|c|}{ Critical load } & \multirow{2}{*}{$\left(\frac{\mathrm{FEA}}{\mathrm{ECP}}\right)$} & \multirow{2}{*}{$\left(\frac{\text { FEA }}{\text { EURO }}\right)$} & \multirow{2}{*}{$\left(\frac{\mathrm{FEA}}{\mathrm{AISI}}\right)$} \\
\hline & & & FEA & ECP & EURO & AISI & & & & FEA & ECP & EURO & AISI & & & \\
\hline HFB2 & \multirow{6}{*}{ G300 } & \multirow{2}{*}{2000} & 27.6 & 29.15 & 29.14 & 29 & 0.946 & 0.946 & 0.95 & 24.978 & 25.262 & 25.25 & 25.15 & 0.989 & 0.989 & 0.993 \\
\hline HFB4 & & & 15.1 & 14.95 & 14.9 & 14.8 & 1.01 & 1.013 & 1.02 & 13.891 & 13.214 & 13.18 & 13.1 & 1.051 & 1.054 & 1.06 \\
\hline HFB2 & & \multirow{2}{*}{3000} & 19.5 & 18.74 & 18.73 & 18.7 & 1.043 & 1.043 & 1.045 & 17.722 & 16.24 & 16.23 & 16.17 & 1.091 & 1.092 & 1.096 \\
\hline HFB4 & & & 8.97 & 9.61 & 9.582 & 9.52 & 0.934 & 0.936 & 0.943 & 8.6135 & 8.4944 & 8.473 & 8.422 & 1.014 & 1.017 & 1.023 \\
\hline HFB2 & & \multirow{2}{*}{4000} & 14 & 13.81 & 13.8 & 13.8 & 1.012 & 1.013 & 1.013 & 12.312 & 11.966 & 11.96 & 11.91 & 1.029 & 1.029 & 1.034 \\
\hline HFB4 & & & 6.81 & 7.081 & 7.06 & 7.02 & 0.962 & 0.965 & 0.97 & 6.0895 & 6.259 & 6.243 & 6.206 & 0.973 & 0.975 & 0.981 \\
\hline \multicolumn{3}{|c|}{ MEAN } & 15.3 & 15.56 & 15.54 & 15.47 & 0.985 & 0.987 & 0.99 & 13.93 & 13.57 & 13.56 & 13.49 & 1.027 & 1.028 & 1.033 \\
\hline \multicolumn{3}{|c|}{$\mathrm{COV}$} & 0.49 & 0.502 & 0.504 & 0.504 & 0.044 & 0.044 & 0.042 & 0.485 & 0.495 & 0.496 & 0.497 & 0.042 & 0.042 & 0.041 \\
\hline
\end{tabular}

Table 3: Comparison of FEA results and the critical load from current design codes (G300 steel)

\begin{tabular}{|c|c|c|c|c|c|c|c|c|c|c|c|c|c|c|c|c|}
\hline \multirow{3}{*}{ Model } & \multirow{3}{*}{$\begin{array}{c}\text { Steel } \\
\text { Grade }\end{array}$} & \multirow{3}{*}{$\begin{array}{l}\text { Clear } \\
\text { Span }\end{array}$} & \multicolumn{7}{|c|}{ RHFB } & \multicolumn{7}{|c|}{ THFB } \\
\hline & & & \multicolumn{4}{|c|}{ Critical load } & \multirow{2}{*}{$\left(\frac{\mathrm{FEA}}{\mathrm{ECP}}\right)$} & \multirow{2}{*}{$\left(\frac{\text { FEA }}{\text { EURO }}\right)$} & \multirow{2}{*}{$\left(\frac{\text { FEA }}{\text { AISI }}\right)$} & \multicolumn{4}{|c|}{ Critical load } & \multirow{2}{*}{$\left(\frac{\mathrm{FEA}}{\mathrm{ECP}}\right)$} & \multirow{2}{*}{$\left(\frac{\text { FEA }}{\text { EURO }}\right)$} & \multirow{2}{*}{$\left(\frac{\mathrm{FEA}}{\mathrm{AISI}}\right)$} \\
\hline & & & FEA & ECP & EURO & AISI & & & & FEA & ECP & EURO & AISI & & & \\
\hline HFB2 & \multirow{6}{*}{ G500 } & \multirow{2}{*}{2000} & 47.8 & 49.63 & 49.58 & 49.3 & 0.964 & 0.965 & 0.97 & 42.64 & 43.05 & 43.03 & 42.85 & 0.99 & 0.991 & 0.995 \\
\hline HFB4 & & & 26.2 & 25.09 & 24.99 & 24.8 & 1.045 & 1.049 & 1.057 & 21.48 & 22.14 & 22.05 & 21.92 & 0.97 & 0.974 & 0.98 \\
\hline HFB2 & & \multirow{2}{*}{3000} & 32.8 & 31.91 & 31.88 & 31.7 & 1.028 & 1.028 & 1.034 & 28.79 & 27.67 & 27.66 & 27.55 & 1.04 & 1.041 & 1.045 \\
\hline HFB4 & & & 15.6 & 16.13 & 16.06 & 16 & 0.967 & 0.971 & 0.975 & 14.45 & 14.24 & 14.18 & 14.09 & 1.015 & 1.019 & 1.025 \\
\hline HFB2 & & \multirow{2}{*}{4000} & 24.5 & 23.51 & 23.49 & 23.3 & 1.042 & 1.043 & 1.051 & 21.07 & 20.39 & 20.38 & 20.3 & 1.033 & 1.034 & 1.038 \\
\hline HFB4 & & & 11.7 & 11.89 & 11.84 & 11.8 & 0.986 & 0.99 & 0.993 & 10.56 & 10.49 & 10.45 & 10.38 & 1.006 & 1.01 & 1.016 \\
\hline \multicolumn{3}{|c|}{ MEAN } & 26.4 & 26.36 & 26.31 & 26.15 & 1.003 & 1.005 & 1.011 & 23.2 & 23 & 23 & 22.8 & 1.007 & 1.009 & 1.014 \\
\hline \multicolumn{3}{|c|}{$\mathrm{COV}$} & 0.49 & 0.508 & 0.509 & 0.509 & 0.037 & 0.037 & 0.038 & 0.493 & 0.501 & 0.503 & 0.503 & 0.026 & 0.025 & 0.025 \\
\hline
\end{tabular}

Table 4: Comparison of FEA results and the critical load from current design codes (G500 steel) 


\subsection{Analysis of stiffened beams}

Stiffeners were simulated using shell elements separated from the beams and connected to them by screws (by coupling points as previously explained). The stiffeners are connecting the top and lower flanges from both side of the beam. The objective from stiffening was to reduce the distortional buckling which occurs during the loading. Tables 5 and 6 show the variations in section load carrying capacities for different positions of the vertical stiffeners. It was noted that the section capacity was affected by changes in the location of the stiffeners. Overall, the change in the load wasn't significant but the failure mode could be changed from stiffening condition to another, Tables 5 and 6 present the failure modes for the HFBs at three stages at yielding point (1), failure point (3), and within yielding zone (2), as shown in Figure 16 (As an example for all beams).

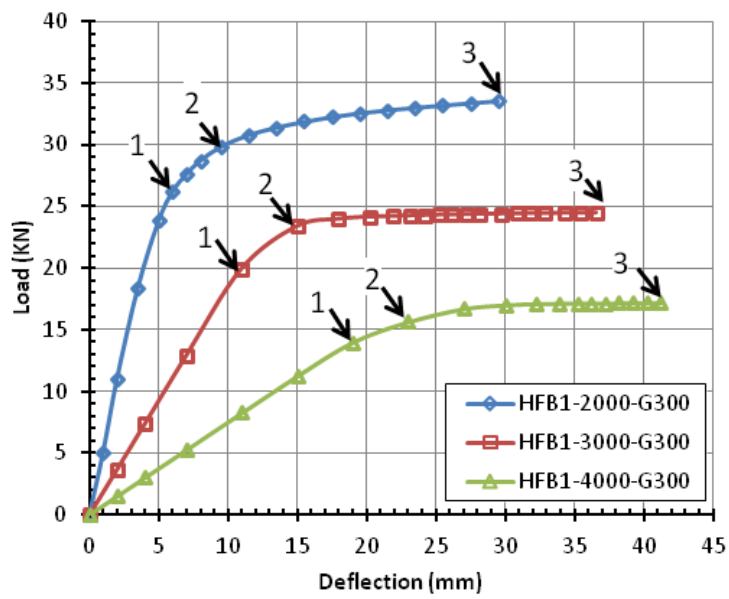

Figure 16: Typical moment versus deflection curves for HFB1 with three different spans $2000 \mathrm{~mm}, 3000 \mathrm{~mm}$ and
$4000 \mathrm{~mm}$ showing the three locations obtained for estimate failure modes.

\subsection{Effect of using vertical stiffeners}

From Tables 5 and 6 , it was found that the stiffener condition $0.05 \mathrm{~L}$ was more effective than both $0.1 \mathrm{~L}$ and $0.2 \mathrm{~L}$ conditions, while stiffener $0.1 \mathrm{~L}$ was more effective than stiffener $0.2 \mathrm{~L}$ conditions. Figures 17-18 illustrated the effect of stiffeners on the section loads. It was found that the stiffeners have small effect on the section load carrying capacity. In some cases, it is even possible to reduce the value of the section capacity as the stiffener locations could possibly lead to a different load mechanism that move the failure location to another weaker point at which failure occurs. Figure 19 shows the deformation of RHFB2 with span of $2000 \mathrm{~mm}$ and four stiffening conditions at failure. It can be seen in Figure 19 a that both the section twist and web distortion occurred mostly between the loading points in the middle third of the beam, also it can be seen in Figure 19b that the failure occurred in the middle third as well but the twisting in section does not exist and the web buckle prior the failure due to bending.

Table 4: Comparison of results between the critical loads obtained for the RHFBs with four conditions of stiffeners and their failure modes.

\begin{tabular}{|c|c|c|c|c|c|c|c|c|c|c|c|c|c|c|c|c|}
\hline \multirow{3}{*}{ Model } & \multicolumn{16}{|c|}{ RHFBs } \\
\hline & \multirow{2}{*}{ Control } & \multicolumn{3}{|c|}{ Failure Mode } & \multirow{2}{*}{$0.05 \mathrm{~L}$} & \multicolumn{3}{|c|}{ Failure Mode } & \multirow{2}{*}{$0.1 \mathrm{~L}$} & \multicolumn{3}{|c|}{ Failure Mode } & \multirow{2}{*}{$0.2 \mathrm{~L}$} & \multicolumn{3}{|c|}{ Failure Mode } \\
\hline & & 1 & 2 & 3 & & 1 & 2 & 3 & & 1 & 2 & 3 & & 1 & 2 & 3 \\
\hline HFB 1-2000-G300 & 27.56 & LBW & LTB & LTB & 28.16 & LBW & LBW & BF & 27.43 & LBF & LBF & BF & 27.00 & LBF & LBW & LBW \\
\hline HFB 2-2000-G300 & 15.09 & LBW & LTB & DB & 15.32 & LBW & LBW & BF & 15.21 & LBW & LBW & BF & 15.13 & LBW & LBW & LTB \\
\hline HFB 1-3000-G300 & 19.54 & LBW & LTB & LTB & 19.56 & LBW & LTB & LTB & 19.56 & LBW & LTB & LTB & 19.55 & LBW & LTB & LTB \\
\hline HFB 2-3000-G300 & 8.97 & LBW & LBF & DB & 9.01 & LBW & LTB & BF & 8.99 & LBW & LTB & BF & 8.99 & LBW & LTB & BF \\
\hline HFB 1-4000-G300 & 13.97 & LBW & LTB & BF & 13.95 & LBW & LTB & BF & 13.93 & LTB & LBW & BF & 13.93 & LTB & LBW & BF \\
\hline HFB 2-4000-G300 & 6.81 & LBF & LBW & DB & 6.81 & LTB & LBW & LBW & 6.81 & LTB & LBW & LBW & 6.81 & LTB & LBW & LBW \\
\hline HFB 1-2000-G500 & 47.84 & LBW & LBF & DB & 48.49 & LBW & LTB & BF & 48.19 & LBW & LTB & BF & 47.89 & LBW & LTB & DB \\
\hline HFB 2-2000-G500 & 26.21 & LBW & LBF & BF & 26.65 & LBW & LBW & BF & 26.44 & LBW & LBW & $\mathbf{B F}$ & 26.29 & LBW & LBW & BF \\
\hline HFB 1-3000-G500 & 32.79 & LBW & LBW & BF & 32.82 & LBW & LBW & BF & 32.81 & LBW & LBW & BF & 32.80 & LBW & LBW & LTB \\
\hline HFB 2-3000-G500 & 15.59 & LBW & LTB & DB & 15.59 & LBW & LBW & $\mathbf{B F}$ & 15.59 & LBW & LBW & BF & 15.59 & LBW & LBW & BF \\
\hline HFB 1-4000-G500 & 24.49 & LBW & LTB & BF & 24.53 & LBW & LTB & BF & 24.51 & LBW & LTB & BF & 24.49 & LBW & LTB & BF \\
\hline HFB 2-4000-G500 & 11.72 & LBF & LBW & DB & 11.72 & LBW & LBW & BF & 11.71 & LTB & LTB & BF & 11.71 & LTB & LTB & BF \\
\hline
\end{tabular}


Table 5: Comparison of results between the critical loads obtained for the THFBs with four conditions of stiffeners and their failure modes.

\begin{tabular}{|c|c|c|c|c|c|c|c|c|c|c|c|c|c|c|c|c|}
\hline \multirow[b]{2}{*}{ Model } & \multicolumn{16}{|c|}{ THFBs } \\
\hline & Control & \multicolumn{3}{|c|}{ Failure Mode } & $0.05 \mathrm{~L}$ & \multicolumn{3}{|c|}{ Failure Mode } & $0.1 \mathrm{~L}$ & \multicolumn{3}{|c|}{ Failure Mode } & $0.2 \mathrm{~L}$ & \multicolumn{3}{|c|}{ Failure Mode } \\
\hline HFB 1-2000-G300 & 24.98 & LBF & LBW & DB & 25.65 & LBW & LBF & LTB & 25.39 & LBW & LBF & LTB & 25.22 & LBF & LTB & LTB \\
\hline HFB 1-3000-G300 & 17.72 & LBF & LBW & DB & 18.19 & LBW & LBF & LTB & 18.10 & LBW & LBF & LTB & 18.0 & LBW & LBF & $\overline{\text { LTB }}$ \\
\hline HFB 2-3000-G300 & 8.61 & LTB & LTB & BF & 8.58 & LBW & LBF & BF & 8.57 & LBW & LBF & BF & 8.57 & LBW & LBF & BF \\
\hline HFB 1-4000-G300 & 12.31 & LBW & LTB & BF & 12.33 & LBW & LBW & BF & 12.33 & LBW & LBW & BF & 12.32 & LBW & LTB & BF \\
\hline HFB 1-2000-G500 & 42.63 & LBW & LTB & BF & 43.59 & LBW & LBF & LTB & 43.26 & LBF & LTB & LTB & 43.18 & LBF & LTB & LTB \\
\hline HFB 2-2000-G500 & 21.48 & LBF & LBW & DB & 21.24 & LBF & LTB & LTB & 21.21 & LBW & LTB & BF & 21.19 & LBF & LTB & LTB \\
\hline HFB 1-3000-G500 & 28.79 & LBW & LTB & BF & 28.65 & LBW & LTB & BF & 28.62 & LBF & LBF & BF & 28.60 & LBW & LTB & BF \\
\hline HFB 2-3000-G500 & 14.45 & LBF & LBF & BF & 14.46 & LBF & LBF & BF & 14.43 & LTB & LBW & BF & 14.42 & LBF & LBF & BF \\
\hline HFB 1-4000-G500 & 21.07 & LBW & LTB & BF & 21.12 & LTB & LBW & BF & 21.10 & LBW & LBW & LTB & 21.09 & LTB & LBW & BF \\
\hline HFB 2-4000-G500 & 10.56 & LTB & LBW & $\mathbf{B F}$ & 10.59 & LBW & LTB & BF & 10.58 & LBW & LTB & $\mathbf{B F}$ & 10.57 & LBW & LTB & BF \\
\hline
\end{tabular}

Beams RHFB2-2000-0.1L-G300 and RHFB2-2000-0.2LG300 were close in section deformation to RHFB2-20000.05L-G300, but in Figure 19d the failure mode occurs due to the local buckling in the web. In general, the stiffeners could change the deformation and failure mode for beams but their effect on the section load capacity was noticed to be small.

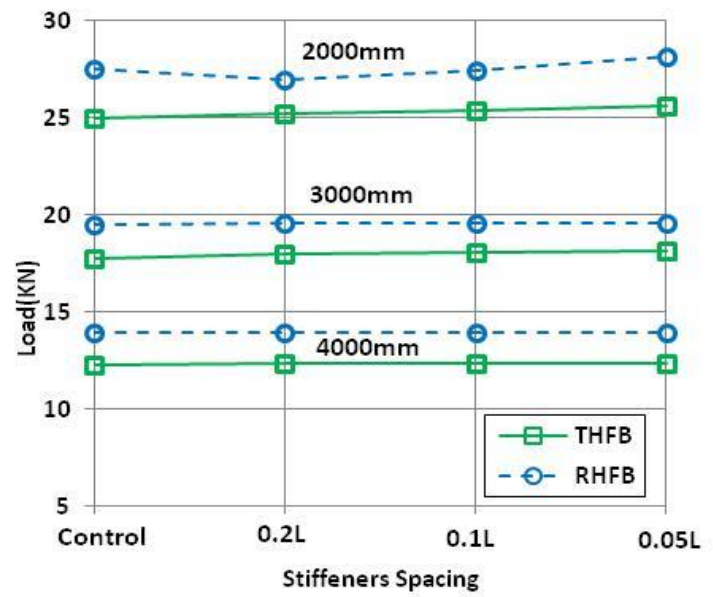

(a) HFB1-G300

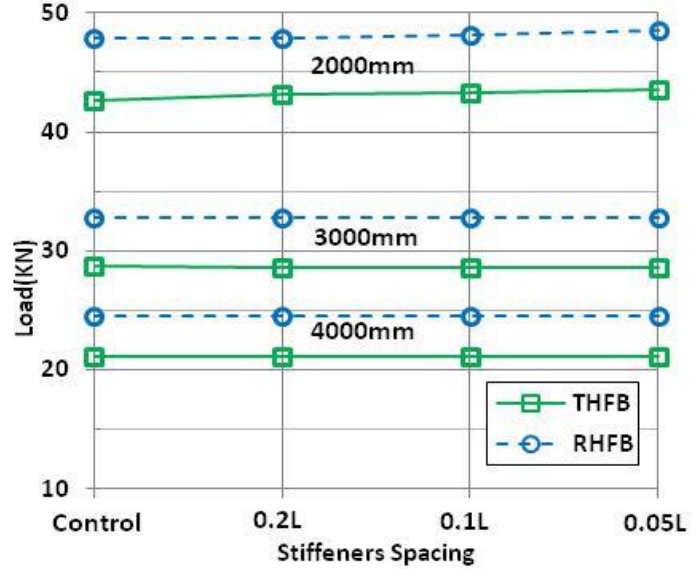

(b) HFB1-G500

Figure 17: Comparison between RHFB1 and THFB1 results with stiffeners.

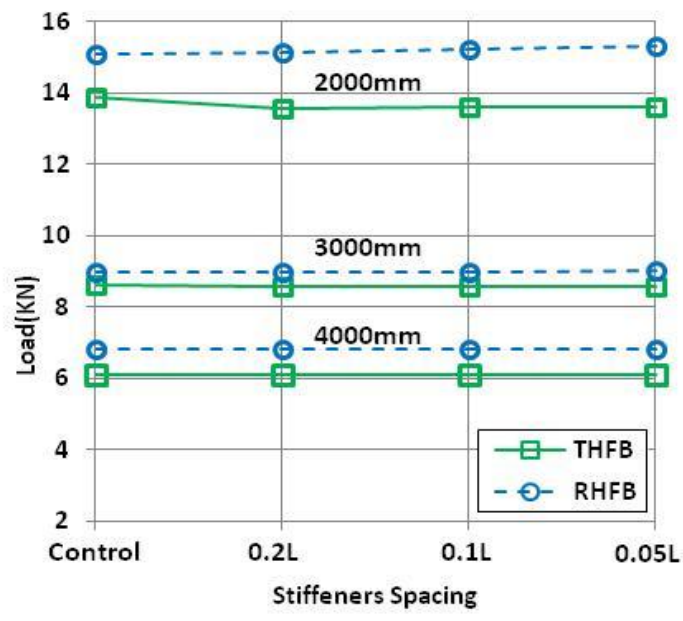

(a) HFB2-G300 


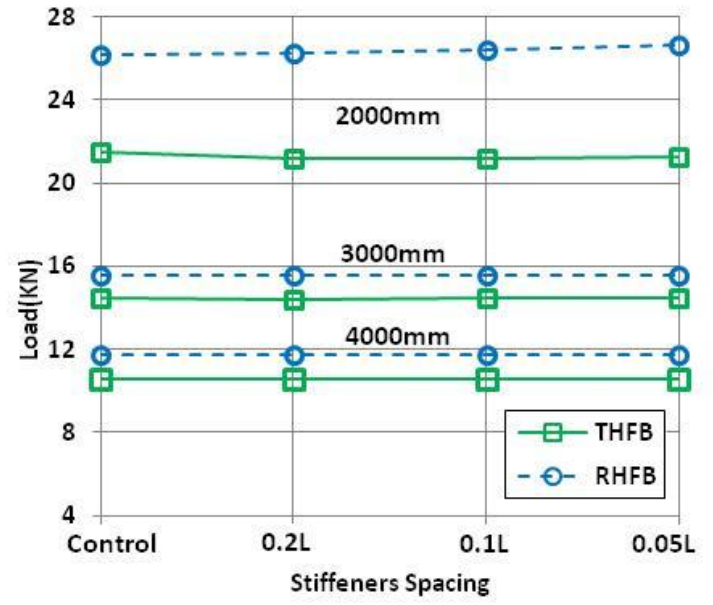

(b) HFB2-G500

Figure 18: Comparison between RHFB2 and THFB2 results with stiffeners.

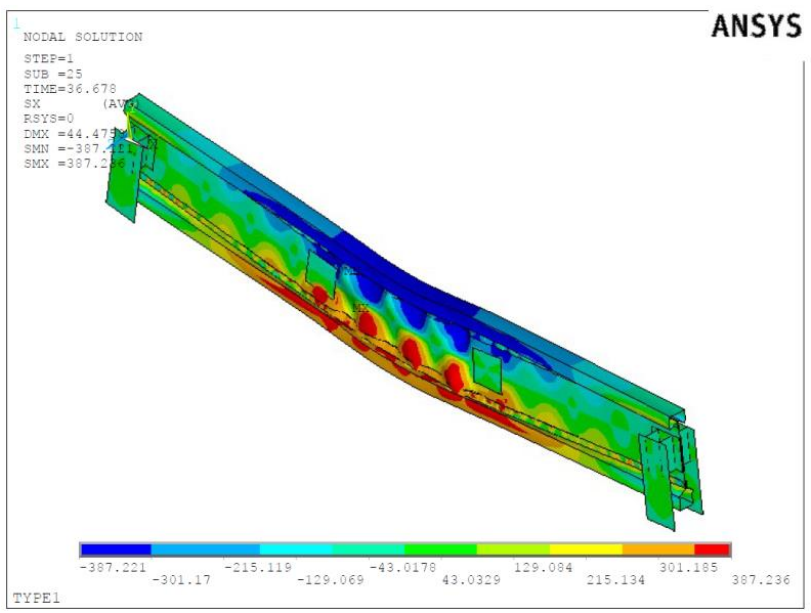

(a) RHFB2-2000-Control-G300

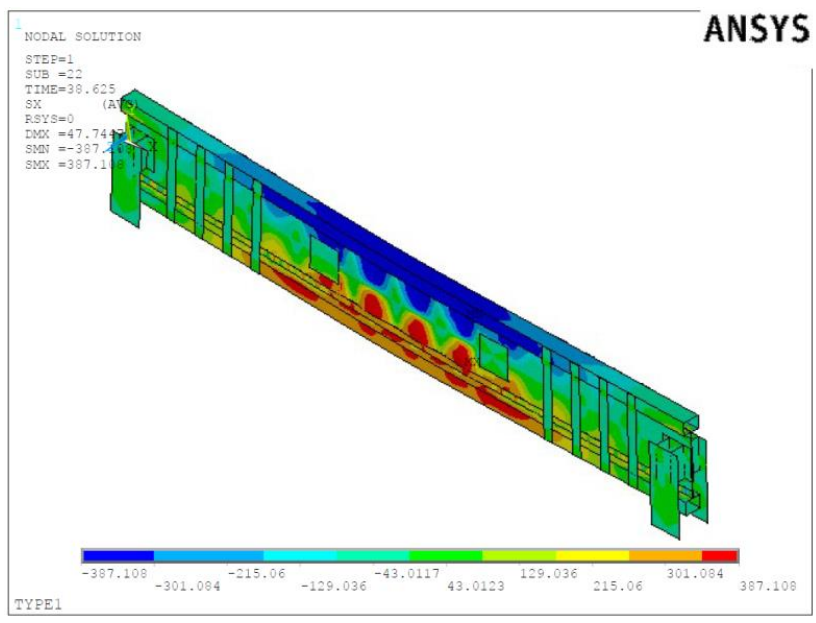

(b) RHFB2-2000-0.05L-G300

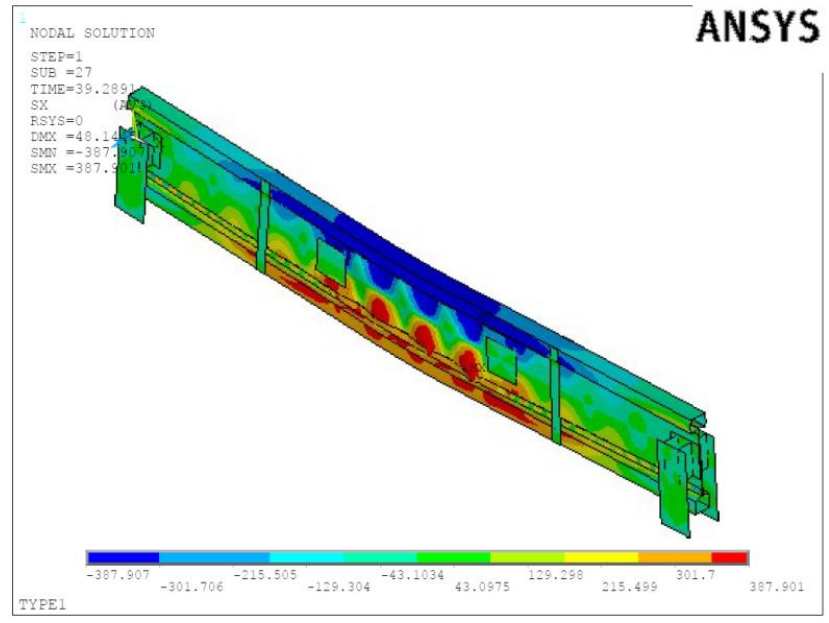

(c) RHFB2-2000-0.1L-G300

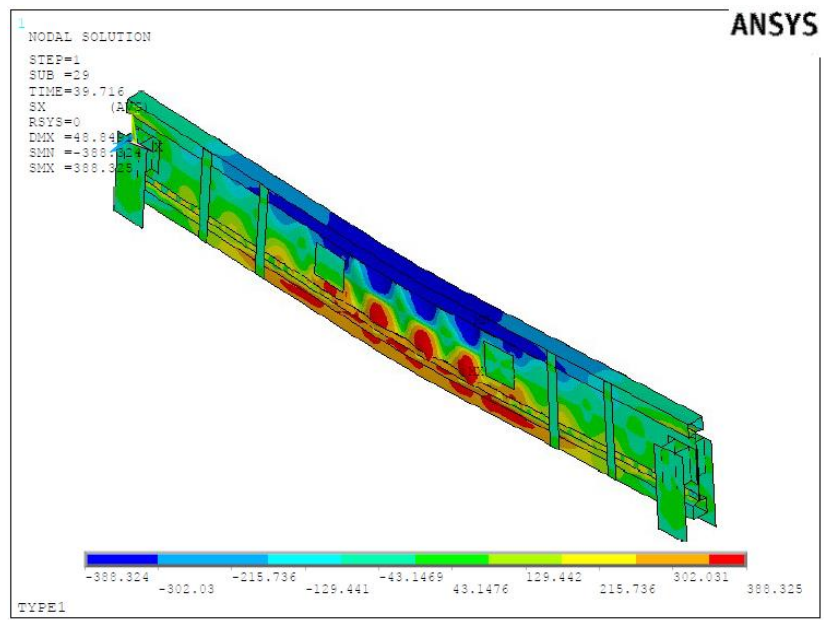

(d) RHFB2-2000-0.2L-G300

Figure 19: Failure modes for RHFB2.

\subsection{Failure types of hollow flanged beams}

Hollow flange beams could fail in different modes such as local buckling, lateral torsional buckling, distortional buckling, and bending failure, as shown in Figures 20 and 21. Local buckling occurs due to applying the loads on the section, with the aid of the geometrical imperfections, which causes yielding in material. By increasing the load level, the lateral torsional buckling then distortional buckling occurs which cause the ultimate stress failure in the beam. Some models did not reach to the ultimate stress failure in material because the failure was due to buckling. It can be realized from Table 5, that most of the RHFBs models had local buckling in web as first failure mode even with the stiffening conditions. But, in case of models with span 4000, HFB1-4000-G300 failed due to local buckling in web and by using the different stiffening conditions as $0.1 \mathrm{~L}$ and $0.2 \mathrm{~L}$ lateral torsional buckling failure took place. Also, model HFB2-4000-G300 had local buckling in flange and by using the different stiffening conditions it failed due to lateral torsional buckling. Model HFB2-4000-G500 failed due to local buckling in flange and when using stiffening condition 
$0.05 \mathrm{~L}$ failure changed to be local buckling in web then changed to be lateral torsional buckling for conditions $0.1 \mathrm{~L}$ and $0.2 \mathrm{~L}$. Table 6 , shows that the first failure modes for THFBs were varied between local buckling in web and local buckling in flange and sometimes was lateral torsional buckling. Therefore, it is obvious that buckling failure is the main failure mode for these types of beams.
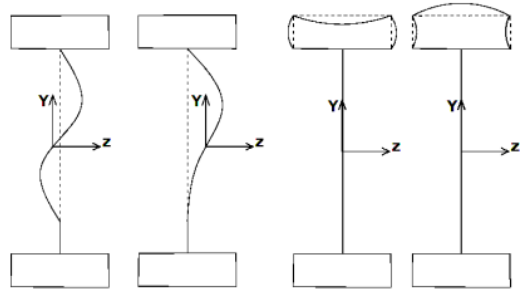

Figure 20: Unsymmetrical local buckling for RHFBs.

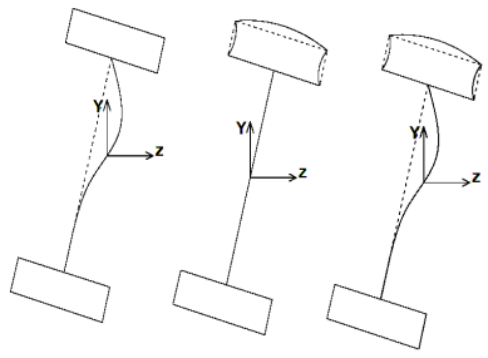

(a) Lateral torsional buckling

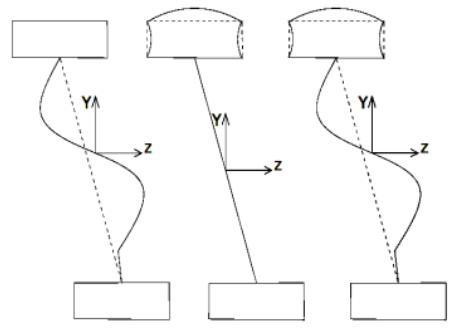

(b) Distortional buckling

Figure 21: Unsymmetrical global buckling for RHFBs.

\subsection{Effect thickness change}

The change of thickness has a large influence on the section load carrying capacities. Figure 22a shows that HFB1, which has web thickness less than the flange thickness, has a critical load varies between $27.6 \mathrm{kN}$ up to $33.2 \mathrm{kN}$, while HFB2, which has web thickness larger than the flange thickness, has a critical load varies between $15.1 \mathrm{kN}$ up to $19.4 \mathrm{kN}$. Moreover, Figure $22 \mathrm{~b}$ shows that HFB1 has critical load ranging from $47.8 \mathrm{kN}$ up to $50.1 \mathrm{kN}$, while HFB2 has critical load ranging from $26.2 \mathrm{kN}$ to $34.1 \mathrm{kN}$. By comparing these results, it is very clear that increasing flange thickness is more effective than increasing web thickness. Thus, increasing flange thickness can enhance the section load capacity much more than that can be done by increasing web thickness.

\subsection{Effect of steel grade}

Figure 22a shows that model HFB1-Control-2000-G300 reached an ultimate load $33.2 \mathrm{kN}$ and a maximum deflection 25.5mm, and model HFB2-Control-2000-G300 reached an ultimate load $19.4 \mathrm{kN}$ and a maximum deflection $30.67 \mathrm{~mm}$.

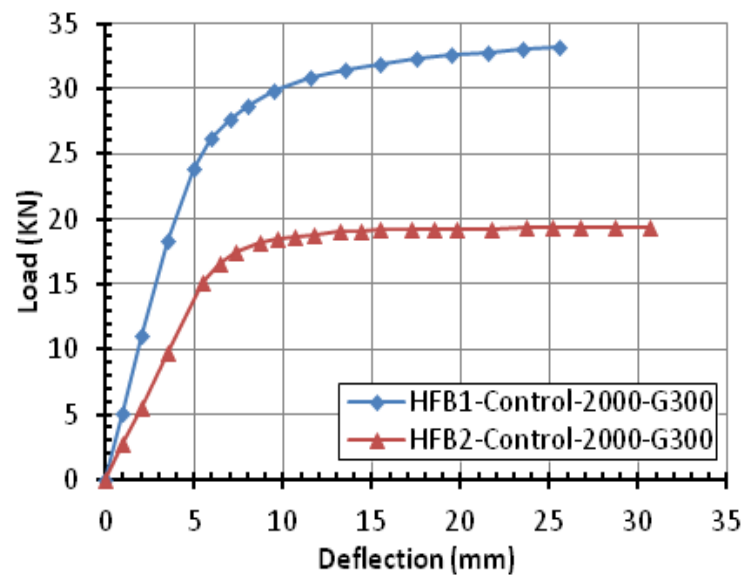

(a) RHFBs with steel grade G300

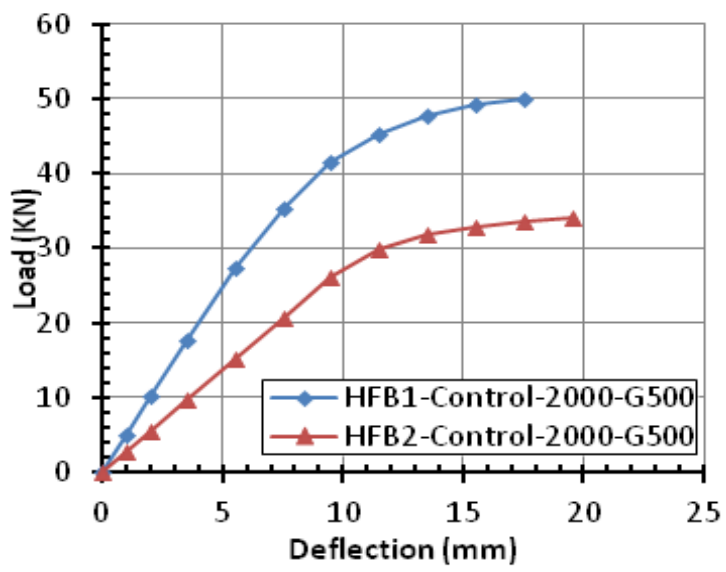

(b) RHFBs with steel grade G500.

Figure 22: Load versus deflection curves for HFB1 and HFB2 with span $2000 \mathrm{~mm}$ and two different steel grades.

Also, Figure 22b shows that HFB1-Control-2000-G500 reached an ultimate load $50.06 \mathrm{kN}$ and a maximum deflection 17.5mm, and HFB2-Control-2000-G500 reached an ultimate load $34.1 \mathrm{kN}$ and a maximum deflection $19.5 \mathrm{~mm}$. By comparing results of HFB1Control-2000-G300 with HFB1-Control-2000-G500 and of HFB2-Control-2000-G300 with HFB2-Control-2000G500 it can be noticed - as can be expected due to the material properties- that beams with steel grade G300 have maximum load less than those of beams with steel grade G500. Also, the deflection in beams with steel grade G300 is larger than deflection in beams with steel grade G500. By studying the effect of steel grade on beams failure modes in Table 5, it was found that steel grade has large effect on the second and third failure modes of RHFBs. For example, in model HFB1-2000G300, failure modes were LBW then LTB up to failure while in model HFB1-2000-G500 failure modes became LBW then LBF then DB. Also, it was found that beams with G500 were more resisting to lateral and distortional 
buckling than beams with G300. Table 6 shows that, the effect of steel grade on the resulted ultimate load and deflection is remarkable. However, due to the flange shape the THFBs do not have the same lateral torsional buckling behavior as for RHFBs. Therefore, steel grade has a strong influence on the ultimate load, the maximum deflection and the failure mode.

\subsection{Effect of increasing span length}

Figure 23 ( $\mathrm{a}$ and $\mathrm{b}$ ) shows comparison between the three different spans versus maximum load for RHFBs and THFBs. It is found that the beam maximum load decreases by increasing the beam span for all models. For example, RHFB1-Control-G300 has reached maximum load $27.56 \mathrm{kN}$ for span $2000 \mathrm{~mm}$ and this value decreased to be $19.54 \mathrm{kN}$ for span $3000 \mathrm{~mm}$ then decreased to be $13.97 \mathrm{kN}$ for span $4000 \mathrm{~mm}$. Furthermore, the variation between maximum load for spans $2000 \mathrm{~mm}$ and $3000 \mathrm{~mm}$ was larger than that variation between spans $3000 \mathrm{~mm}$ and $4000 \mathrm{~mm}$. This means that short spans are more effective than large spans due to the different anticipated failure load as discussed earlier. For the beams with similar section type, span length, and steel grade and with different dimensions (HBF1 and $\mathrm{HBF} 2$ ), the difference between maximum load decreases by using larger spans. For example, in RHFBs models: the difference between maximum load for span 2000mm for HFB1-Control-G300 and HFB2-Control-G300 is $(27.56 \mathrm{kN}-15.09 \mathrm{kN}=$ $12.47 \mathrm{kN})$ while, for span $3000 \mathrm{~mm}$ is $(19.54 \mathrm{kN}-8.97 \mathrm{kN}$ $=10.57 \mathrm{kN})$ and for span $4000 \mathrm{~mm}$ is $(13.97 \mathrm{kN}-6.81 \mathrm{kN}$ $=7.16 \mathrm{kN})$. This means that the effect of thickness is influenced by the change in beam span.

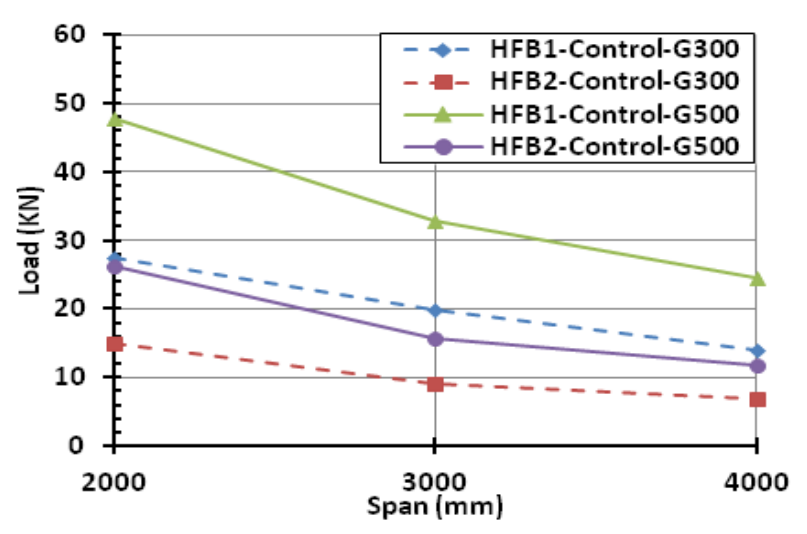

(a) RHFBs

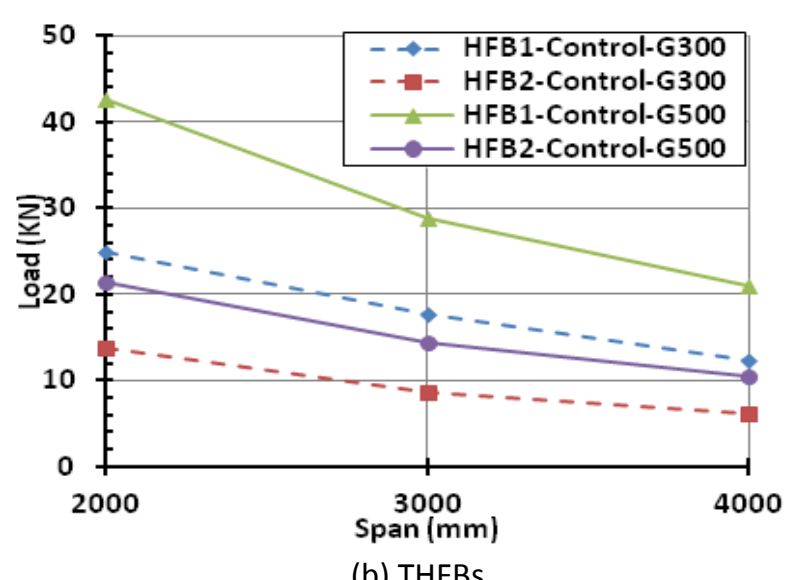

(b) THFBs

Figure 23: Load versus span curves for HFB1 and HFB2 with two different steel grades. (a) for RHFBs and (b) for THFBs.

\subsection{Effect of section shape}

From Table 5, RHFBs almost have similar first failure mode then due to the effects of steel grade, stiffening conditions and span failure modes changed. Until failure, While for THFBs in Table 6 the behavior is not similar in the three stages of failure. This difference between the behavior of the two shapes refers to the section flanges shape and the section behavior against its initial geometric imperfections under flexure. From Figures 17-18, it can be seen that the RHFBs load results are better than THFBs results specially with span $2000 \mathrm{~mm}$, whereas the variance between load results in span $2000 \mathrm{~mm}$ was larger than the variance in spans $3000 \mathrm{~mm}$ and $4000 \mathrm{~mm}$. overall, by comparing the results considering all previous effects it has been found that the load results are often close but the RHFBs is effective than THFBs.

\section{CONCLUSIONS}

This paper has presented a detailed investigation about the behavior of a light gauge hollow flange beams under flexure using the finite element analysis. This study included a verification using the FEA of a five RHFB sections that were tested to failure under a two-point loading configuration. Finite element models were constructed to simulate the tested beams with respect to loading and boundary conditions. The finite element models' failure modes, ultimate strengths, and momentdeflection and moment-strain plots were obtained. The results from the FEA demonstrate good agreement with experimental results. Parametric study was performed by using the verified finite element models of the RHFB to study the influences of using different web and flange thicknesses, flange shape, location of the stiffeners, and beams spans. The results were compared with those predicted based on design rules using two different design codes. The results demonstrate very good agreement as well.

The parametric study shows that: 
- Using vertical stiffeners changes the mode of failure, but its influence on improving the beam load carrying capacity is very small.

- Failure due to various types of buckling is the main failure mode for these types of beams.

- The improve in beam loading capacity and its overall behavior due to using larger flange thickness is rather more than the improve due to increasing the web thickness for such beams.

- Steel grade has a large effect on the HFBs load capacity, maximum deflection, and failure mode.

- For RHFBs, increasing steel grade could be efficient in resisting the lateral buckling.

- Using RHFBs is more effective than using THFBs. Such effects should be considered in the design of HFBs under flexure.

\section{REFERENCES}

[1] P.Avery, Mahen Mahendran, (1996), Finite Element Analysis of Hollow Flange Beams with Web Stiffeners, International Specialty Conference on Cold-Formed Steel Structures.

[2] Pi, Trahair, (1997), Lateral-Distortional Buckling of Hollow Flange Beams, Journal of Structural Engineering, (ASCE) 0733-9445, Vol. 123,No 6, pp (695-702).

[3] Zhao, W., (2005), "Behaviour and design of coldformed steel hollow flange sections under axial compression", PhD Thesis, School of Civil Engineering, Queensland University of Technology, Brisbane, Australia.

[4] Somadasa,W.,(2005), Flexural Behaviour and Design of Cold-formed Steel Beams with Rectangular Hollow Flanges, PhD thesis, Queensland University of Technology.

[5] Anapayan T, Mahendran M, Mahaarachchi D., (2011). Section moment capacity tests of LiteSteel beams. ThinWall Structure, 49:502-12.

[6] Anapayan T, Mahendran M., (2012), Improved design rules for hollow flange sections subject to lateral distortional buckling. Thin-Wall Structure, 50:128-40.

[7] Anapayan T, Mahendran M, Mahaarachchi D., (2011), Lateral distortional buckling tests of a new hollow flange channel beam. Thin-Wall Structure, 49:13-25.

[8] Anapayan T, Mahendran M., (2012), Numerical modeling and design of LiteSteel beams subject to lateral buckling, Journal of Constriction Steel Research, 70:5164.
[9] Mahendran M, Keerthan P., (2013), Experimental studies of the shear behaviour and strength of LiteSteel beams with stiffened web openings, Engineering Structure, 49:840-54.

[10] Keerthan P, Mahendran M., (2010), Experimental studies on the shear behaviour and strength of LiteSteel beams, Engineering Structure, 32:3235-47.

[11] Keerthan P, Mahendran M., (2011), New design rules for the shear strength of LiteSteel beams, Journal of Construction Steel Research, 67:1050-63.

[12] Keerthan P, Hughes D, Mahendran M., (2013), Experimental studies of hollow flange channel beams subject to combined bending and shear actions. Thin-Wall Structure, 77:129-40.

[13] Mahen Mahendran and Dhammika Mahaarachchi, (2006), Section moment capacity of a new cold-formed hollow flange, International Specialty Conference on Cold-Formed Steel Structures, Paper 8.

[14] Tim Wilkinson, Patrick Liu, Jester Magpayo, and Huong Nguyen, (2006), Increasing the strength and stiffness of cold-formed hollow flange, International Specialty Conference on Cold-Formed Steel Structures, Paper 5.

[15] Sivapathasunderam Jeyaragan, Mahen Mahendran, (2008), Flexural Behavior and Design of the New Built up LiteSteel Beams, International Specialty Conference on Cold-Formed Steel Structures, Paper 3.

[16] Kurniawan, Cyrilus Winatama and Mahendran, Mahen ,(2009), Lateral buckling strength of simply supported LiteSteel beams subject to moment gradient effects, Journal of Structural Engineering, 135(9). pp. 1058-1067.

[17] Kurniawan, Cyrilus Winatama \& Mahendran, Mahen, (2011), Elastic lateral buckling of cantilever LiteSteel beams under transverse loading, International Journal of Steel Structures, 11(4), pp. 395-407.

[18] V.Raghul, N.Uma Maheswari, (2015), Analytical Investigation on Cold-Formed Steel Built-Up, International Journal of Advanced Engineering Research and Technology (IJAERT), Volume 3 Issue 4, ISSN No.: 2348 - 8190, pp. 108-114.

[19] Mahendran, M., (2007), Applications of Finite Element Analysis in Structural Engineering, Proceedings International Conference on Computer Aided Engineering, pages pp. 38-46, Chennai, India.

[20] ANSYS Mechanical APDL, Ansys Inc.

[21] B.W. Schafer, T. Pekoz, (1998), Computational modeling of cold-formed steel: characterizing geometric 
imperfections and residual stresses, Journal of Constructional Steel Research, No. 47, pp. 193-210.

[22] Hong-Xia Wan, Mahen Mahendran, (2015), Bending and torsion of hollow flange channel beams, Engineering Structures No. 84, pp.300:312.

[23] EN 1993-1-3 (2006) (English): Eurocode 3: Design of steel structures - Part 1-3: General rules Supplementary rules for cold-formed members and sheeting.

[24] EN 1993-1-5 (2006) (English): Eurocode 3: Design of steel structures - Part 1-5: General rules - Plated structural elements.

[25] AISI STANDARD: North American Specification for the Design of Cold-Formed Steel Structural Members 2012 EDITION-Chapter B.

[26] ECP 205-2001: Egyptian code of practice for steel construction and bridges - chapter 2 Allowable stresses and chapter 11: Cold formed sections. 
سلوك الاتحناء للكمرات المصنعة باستخدام قطاعات الصلب الرقيقة ذات الثفة المفرغة المستطيلة أوالمثلثة

د. طارق عبد المنعم شرف - د. أشرف اسماعيل الصباغ - م. محمد عبد اللطيف ـ ا.د. محمد محمد الغندور

\section{ملخص البحث}

على الرغم من أن القطاعات الصلب المدرفلة على الساخن هى الأكثر شيو عاو استخداما فى المنشآت الصلب حتى الآن، إلا أن استخدام


مختلفة من الانبعاج مثل الانبعاج الموضعى، الانبعاج التشوهى، الانبعاج الإلتوائى. كما يتم انتاج قطاعات الصلب الرقيقة بالعديد من الأشكال. أحد هذه الاشكال هى القطاعات ذات الثفة المفرغة، التى أثتتت كفاءتها على بالرغم أنه لم يتم التوصل للفهم الكامل لسلوكها لإنها حتى الآن. فى هذا البحث تم التحقق من سلوك الانحناء لتلك الكمرات باستخدام نظرية العناصر المحددة. نم تطبيق دراسة نظرية عددية للتحقق من المعاملات المختلفة التىى تؤثر على سلوك تللك الكمرات وذلك فى حالة استخدام شفة مفرغة مستطيلة أو مثلثة، فى وجود أو عدم وجود تقويات رأسية، وتحت تأثير أحمال الانحناء. تم تعريض كل الكمر ات بسيطة الارتكاز محل الدراسة لحملين مركزين. ثم تحديد أقصى حمل للكمر ات و أنواع الانهيار فى الحالات المختلفة. نم استخدام ثلاثة أكو اد تصميم مختلفة للتحقق من النتائج. 